\title{
IDENTIDADES EN DESASTRES PROLONGADOS. ESCENARIOS TRANSNACIONALES DESDE LOS CAMPAMENTOS DE REFUGIADOS SAHARAUIS
}

\section{Identities in Longstanding Disasters. Transnational Scenarios from Saharawi Refugee Camps}

\author{
Silvia Almenara Niebla *; Carmen Ascanio Sánchez* \\ * Universidad de La Laguna \\ silvia.almenara@ull.es; cascanio@ull.es
}

Palabras clave

Campamentos de refugiados Cronotopo del desastre Transnacionalismo Identidades Sahara Occidental

\section{Keywords}

Refugee camps Chronotope of disaster Transnationalism Identities Western Sahara

\begin{abstract}
Resumen
Este artículo analiza la construcción de memorias e identidades en campamentos de refugiados de larga duración. La perpetuación de los conflictos transforma, radicalmente, la concepción temporal de estos lugares, que se convierten, según la denominación de algunos autores, en "espacios de espera", "espacios anómalos" o "agujeros espaciotemporales". A través del desarrollo del concepto de "cronotopo" de Bajtín argumentamos, por un lado, que lo que denominamos "cronotopo del desastre" atraviesa el paso del tiempo (generaciones) y los espacios de asentamiento (campamentos y lugares de la diáspora), insertándose en las memorias y el devenir de la identidad; y, por otro lado, que la convivencia de varias generaciones y la movilidad de personas, bienes e informaciones convierten a los campamentos de refugiados en territorios transnacionales, reconfigurando este cronotopo y las políticas de pertenencia desde lo local hacia lo global. Con foco en el caso saharaui y a través de un trabajo etnográfico (multisituado) presencial y virtual, así como de entrevistas y análisis de materiales visuales, se analizan dos etapas de construcción de la identidad: la primera asociada al exilio y al proyecto nacional; la segunda claramente atravesada por los procesos de movilidad y el impacto de las nuevas tecnologías donde emergen nuevas subjetividades.
\end{abstract}

\section{Abstract}

This article analyzes the construction of memories and identities in longstanding refugee camps. The prolongation of conflicts radically changes the perception of refugee camps as temporary settlements. This situation transforms such spaces, according to some authors, into "waiting spaces", "anomalous spaces", or "places lost in time and space". Through the concept of "chronotope" developed by Bajtín, we argue, on the one hand, that what we define as "chronotope of disaster" passes through time (generations) and spaces of settlement (refugee camps and diasporic spaces), entangling with memories and identities; and, on the other hand, that the cohabitation of several generations, mobility of people, goods, and information change refugee camps into transnational spaces, reconfiguring this chronotope and the politics of belonging from the local to the global. Looking at the Sahrawi case through a multisituated ethnographic approach (face-to-face and virtual), as well as interviews and visual analysis, we analyze two stages of identity construction: the first one, related to exile and the national project; the second one, clearly influenced by mobility processes and the impact of new technologies where new subjectivities emerge.

Almenara Niebla, S., y Ascanio Sánchez, C. (2018). Identidades en desastres prolongados. Escenarios transnacionales desde los campamentos de refugiados saharauis. Papeles del CEIC. International Journal on Collective Identity Research, vol. 2018/1, papel 192, CEIC (Centro de Estudios sobre la Identidad Colectiva), UPV/EHU Press, http://dx.doi.org/10.1387/pceic.17661 


\section{INTRODUCCIÓN}

Este artículo aborda procesos de construcción de la identidad en lugares impregnados por el desastre, en concreto en campamentos de refugiados de larga duración. Estos espacios surgen como respuesta temporal a situaciones de crisis de movilidad de grupos de personas a través de las fronteras, aunque en numerosas ocasiones estos escenarios efímeros se prolongan debido a la falta de resolución de los conflictos. El paso del tiempo, la convivencia de varias generaciones, los nuevos procesos de movilidad de personas, bienes e informaciones transforman, en la actualidad, los campamentos de refugiados en territorios transnacionales, generando nuevas dinámicas sociales y reconfigurando políticas de pertenencia. Algunos autores los han analizado como espacios anómalos (Feldman, 2015), espacios de espera (Agier, 2002) o agujeros espaciotemporales (Bauman, 2002) que generan dinámicas sociales y de identidad específicas a la que las personas refugiadas se ven sometidas.

Las migraciones forzadas por conflictos bélicos dejan una huella perenne tanto en las poblaciones afectadas como en las sucesivas generaciones (Sigona, 2014; Ager, 2014; Hajdukowski-Ahmed, 2009). De hecho, todo desplazamiento forzoso produce una crisis cultural, "una suspensión del sentido común y del imaginario acerca de quiénes somos (...) una sensación colectiva de liminalidad, de que algo ha llegado a su fin" (Grimson, 2011: 14-15), que requieren de nuevos regímenes de significación que ofrezcan certidumbres.

La noción de desastre concentra violencias pasadas, traumas del abandono de los lugares de origen, éxodos, asentamientos en territorios de asilo y pérdidas de referentes culturales y simbólicos que atraviesan el paso del tiempo, las generaciones y los espacios, sea en los mismos campamentos o en las diásporas. Paradójicamente, estas experiencias traumáticas que fluctúan entre lo individual (personas desplazadas, exiliadas, encerradas, traumatizadas) y lo colectivo (identidades, estrategias e imaginarios), también aportan nuevos significados a sentimientos y prácticas cotidianas como la nostalgia, la incertidumbre del retorno, las estrategias de supervivencia y, por tanto, la necesidad de fijar el presente y mirar al futuro.

La relación entre las memorias del desastre y el devenir de la identidad que se van fijando en estos espacios anómalos nos sugiere la 
operatividad del concepto de cronotopo (chronotope) que Bajtín (1996) aplicó a los estudios literarios. Sin embargo, es de utilidad en distintos entornos como el de lo social $y$, de hecho, uno de los ámbitos más evocadores es el de las estrategias de representación (Ascanio Sánchez, 2007). El concepto de cronotopo remite a una visión privilegiada del tiempo y del espacio: una especie de promontorio donde ambos se cruzan en una matriz desde la que se puede visibilizar y reconstruir memorias e imaginarios pasados, presentes y futuros. Por tanto, una metáfora como la del "cronotopo del desastre" nos permite rastrear los modos de transmitir, reproducir y negociar memorias relacionadas con el trauma, individual y colectivo, las relaciones de poder y, por supuesto, las huellas que orientan la construcción de la identidad y las políticas de pertenencia.

En el caso saharaui, este cronotopo ha viajado por el tiempo -los cuarenta años de conflicto- y los espacios de asentamiento, campamentos y lugares de la diáspora. Desde ese denso promontorio se ha visualizado el pasado colonial, el exilio, la vida cotidiana y los imaginarios de futuro, impregnando los sentimientos de pertenencia. Para el propósito de este artículo nos centraremos en dos momentos clave en la construcción de memorias e identidades: el primero, asociado al exilio y al proyecto nacional; el segundo, claramente atravesado por los procesos de movilidad y el impacto de las nuevas tecnologías, donde emergen nuevas y complejas subjetividades. Desarrollar ambos momentos a través del "cronotopo del desastre" requiere superar perspectivas posmodernas descontextualizadas sobre las construcciones de la identidad y reponer, como sugiere Stuart Hall (2010), el carácter situado, histórico y casuístico que explique prácticas cotidianas, políticas de pertenencia, relaciones de poder y toma de decisiones a través de la articulación entre cultura, identidad y política.

Para ello, el artículo se desarrolla a través de dos ejes. El primero ofrece una visión general de los campamentos de refugiados de larga duración, surgidos como espacios del desastre y reconfigurados como espacios transnacionales en la actualidad. El segundo, se centra en el caso saharaui y analiza la construcción y fijación del "cronotopo del desastre" en esos dos momentos clave mencionados.

Este análisis surge de las reflexiones mantenidas en el marco de varias líneas de trabajo sobre identidades colectivas, el impacto de las nuevas 
tecnologías en los procesos migratorios y el caso saharaui ${ }^{1}$. La metodología articula, por una parte, la revisión bibliográfica centrada en los estudios de refugiados, diásporas y transnacionalismo, y, por otra parte, un enfoque predominantemente cualitativo basado en etnografias presenciales (multisituadas) y virtuales. Los trabajos de campo se han desarrollado en diversos territorios: en la zona bajo control marroquí (2010), en los campamentos de refugiados saharauis de Tinduf (2016), en la ciudad de Nuadibú —norte de Mauritania- (2017) y en las Islas Canarias (2016-2017). En los dos primeros espacios se han realizado breves incursiones etnográficas, debido a las dificultades de entrada (permisos y visados) y permanencia en estos lugares. En los dos últimos, se ha hecho un trabajo de campo más amplio, con varios períodos de trabajo desde 2016 a la actualidad. La aproximación en línea (2016-2017) se ha focalizado en la comunidad saharaui hispanoangloparlante, residente mayoritariamente en España y algunos países europeos, que posee blogs personales o colectivos o perfiles de Facebook relevantes. Desde este enfoque, hasta el momento, se han desarrollado técnicas de observación, descripción de numerosos eventos, 30 entrevistas (biográficas/temáticas, grupales y a informantes calificados) y análisis visuales (fotografías, videos, memes, íconos).

\section{CAMPAMENTOS DE REFUGIADOS DE LARGA DURACIÓN}

Sesenta y cinco millones de personas se han visto obligadas a desplazarse de su lugar de residencia habitual por motivos de guerras, persecuciones, desastres medioambientales, etc., según el informe de tendencias globales del Alto Comisionado de las Naciones Unidas para los Refugiados (ACNUR, 2016). Los casos más prolongados y que han sido objeto de análisis son los del campamento de Dadaab en Kenia, el campamento de refugiados tamiles en Sri Lanka, los refugiados palestinos en Cisjordania, Gaza, Jordania y Líbano, los refugiados de Darfur en Chad y el de los refugiados saharauis en Argelia. El desastre

\footnotetext{
${ }^{1}$ Por un lado, el proyecto "La construcción de la identidad europea y los extranjeros...: líneas de continuidad y análisis comparativo" (HAR2014-53024-P), financiado por el Ministerio de Economía y Competitividad del Gobierno de España, 2015-2017, donde participa Carmen Ascanio Sánchez. Y, por otro lado, el proyecto doctoral de Silvia Almenara Niebla "Diásporas digitales, género e identidades: procesos, usos y estrategias desde el Sáhara Occidental" cofinanciado por la Agencia Canaria de Investigación, Innovación y Sociedad de la Información de la Consejería de Economía, Industria, Comercio y Conocimiento y por el Fondo Social Europeo (FSE), Programa Operativo Integrado de Canarias 2014-2020, Eje 3.
} 
asociado a la violencia directa del conflicto, la sensación de desposesión y la involuntariedad del proceso migratorio repercuten en la construcción simbólica del sujeto desplazado, que construye su propia realidad a través del trauma del desplazamiento (Coraza, 2014). Así, la configuración de espacios, tiempos y movilidades en el devenir cotidiano de los campamentos resulta clave para comprender el "cronotopo del desastre" y la construcción de identidades.

\subsection{Espacios del desastre}

La configuración del espacio es clave en los procesos de migración forzada, ya que los campamentos de refugiados se crean en lugares aislados o apartados de zonas habitadas. Su objetivo es dar cobijo, seguridad física, alimentos y asistencia médica a las personas que huyen de su pais de origen por miedo a la violencia organizada. Se constituyen, pues, como espacios humanitarios de respuesta a una situación puntual de crisis, pero la inexistencia de políticas de asilo y de inclusión contribuyen a su perpetuación. El paso del tiempo y la poca capacidad de acción de los gobiernos estancan, en muchos casos, esta situación de crisis humanitaria.

De acuerdo con llana Feldman (2015), los campamentos de refugiados son espacios geopolíticos anómalos que responden a la lógica asistencial, donde las personas refugiadas se conciben como simples usuarios del sistema humanitario internacional. En esta línea, se considera que los campamentos de refugiados son "santuarios humanitarios" (Agier, 2002: 319) que se crean como espacios de espera en los bordes del mundo. Ubicada en áreas periféricas de los Estados receptores, cerca de las fronteras, pero también fuera de las ciudades, en los suburbios, dársenas, solares o en áreas rurales, la población refugiada permanece a la expectativa de que su situación se resuelva. Ello corrobora la existencia de estrategias de dispersión dirigidas a la no integración en el país receptor, manteniendo el sistema internacional de Estados nacionales (Turton, 2003). Así, los campamentos de refugiados están "concebidos y planeados como un agujero en el tiempo y en el espacio, una suspensión temporal de la adscripción territorial y de la secuencia temporal" (Bauman, 2002: 114).

Por otra parte, diversos autores se centran en las consecuencias emocionales de estos procesos. En los campamentos de refugiados se respira una atmósfera especial de temporalidad, de hogar provisional y 
de deseo de retorno al lugar de origen. Estos espacios son un "testimonio desnudo de las condiciones de incertidumbre" (Appadurai, 1996: 193), ya que aquí conviven las experiencias de todos aquellos que experimentaron el desplazamiento forzado, los traumas, la desesperación y la ansiedad. Esto configura una nueva realidad en función de las lógicas del régimen humanitario internacional, que construye la noción de víctima y la despoja de su propia capacidad de agencia.

Con todo ello, la población refugiada construye sus propias narrativas sobre la pérdida del lugar al que estaba ligada a través de ciertos atributos de identidad y de pertenencia. Al asumir la condición de víctima del sistema internacional, se crea una problemática relacionada con la identidad, transformando etnicidades en nacionalidades ${ }^{2}$.

Liisa Malkki (1995), en su estudio sobre la comunidad refugiada hutu en Tanzania, argumenta que el escenario de confinamiento y de eventualidad del campamento fortalece el proceso imaginativo de construcción de las naciones e identidades colectivas a través de la creación de una historia-mítica asociada al desplazamiento, mientras que aquellos que no experimentan el aislamiento del campamento y llevan a cabo estrategias de movilidad exterior desarrollan procesos de identidad cosmopolitas. Asimismo, considera que las personas refugiadas dentro de los campamentos tienden a asumir "el orden nacional de las cosas" (Malkki, 1995: 5) y constituir una nación a través de las memorias colectivas, entendidas como "la intención de inscribir en el grupo una trayectoria histórica y espacial (...) que delinee el cuándo, quién y dónde del grupo, así como su consolidación y reproducción a través del tiempo y del espacio" (Lacroix y FiddianQasmiyeh, 2013: 685). Siguiendo esta línea de análisis, Randa Farah (2008) afirma, a través de los casos palestino y saharaui, que los campamentos de refugiados pueden convertirse en incubadoras de organizaciones políticas y memorias colectivas. El desastre del confinamiento, por tanto, se configura como un canalizador de

\footnotetext{
${ }^{2}$ Esto lo analiza Michel Agier (2002) en el campamento de Ifo donde, a pesar de que la mayoría de los refugiados pertenecían a grupos étnicos diferentes, se identificaban como etíopes, lo que había reforzado, de forma operativa, su adscripción territorial y rebajado su afiliación étnica inicial. Para este mismo autor, el campamento en sí se convierte en un entorno donde surge una estrategia de identidad; ciertamente las identidades nacionales y étnicas de los grupos han surgido antes del campamento, pero se transforman, funden o se separan en el interior de este espacio.
} 
identidades y de resistencias que se vinculan directamente con el espacio de aislamiento al que las comunidades refugiadas se ven abocadas, en una situación de suspensión momentánea de la ciudadanía.

Además, los roles de género juegan un papel fundamental, ya que hombres y mujeres se sitúan en diferentes posiciones en relación con las políticas de pertenencia, asignando a ellas el papel de reproductoras simbólicas e ideológicas de las identidades colectivas de las comunidades (Yuval-Davis y Anthias, 1989). Así pues, las nociones de tiempo y espacio se condensan de modo plural, dependiendo de las vivencias de las personas refugiadas. En los campamentos conviven, por una parte, personas que experimentaron el desplazamiento, cuyas memorias conectan directamente con los lugares de origen basados en referentes materiales, simbólicos, afectivos, culturales y políticos, y, por otra parte, personas que no vivieron el proceso de migración forzada pero que lo reviven a través de memorias familiares, construyendo políticas de pertenencia desde las que se interioriza el trauma (Loizos, 2007).

Es aquí donde nuestra propuesta del "cronotopo del desastre" resulta útil en el análisis de este tipo de situaciones, articulando de forma compleja las propias vivencias de los hombres y las mujeres, así como las memorias trasmitidas entre generaciones.

\subsection{Escenarios transnacionales}

A pesar de que los campamentos de refugiados son espacios de movilidad restringida, la larga duración del asentamiento genera nuevos procesos asociados a la dilación del desastre. Si bien la desposesión a la que se ve sometido el sujeto, en un primer momento, lo categoriza como víctima y limita su capacidad de agencia, es a través de las prácticas transnacionales donde va adquiriendo mayor autonomía y posibilidades de reinventar su propio presente. Por ello, la movilidad de personas, bienes, servicios, informaciones y simbolos reconfigura identidades y genera nuevas subjetividades, asociadas a la experiencia, propia y ajena, fuera del confinamiento de los campamentos.

A mediados de los 90 , los flujos de movilidad de las personas comienzan a ser analizados bajo el prisma del transnacionalismo. Su inicial descripción vincula dicha noción a procesos en los que un considerable 
número de personas desarrollan ocupaciones y actividades, periódicas y sostenidas en el tiempo, a través de las fronteras nacionales (Portes, Guarnizo y Landolt, 1999). La popularización del término inicia una relevante producción científica sobre la movilidad fisica y continua de individuos, sus prácticas y vínculos entre sus áreas de origen y las de destino (Guarnizo, 2003; Kivisto, 2001), la simultaneidad de prácticas y vínculos entre las diversas fronteras nacionales (Levitt y Glick Schiller, 2004), la coparticipación económica y política entre diversos agentes y la reconstrucción de vínculos y solidaridades entre territorios (Faist, 2000). Esta perspectiva ha sido de especial relevancia para reflexionar sobre las conexiones entre territorios, al tener en cuenta la multitud de puntos de retroalimentación que une a lugares de origen y destino, cuestionando el nacionalismo metodológico (O'Reilly, 2012) y reformulando conceptos como cultura, identidad y espacio que habian sido restringidos a las fronteras nacionales.

No obstante, los estudios sobre migraciones forzadas han seguido anclados en la perspectiva del nacionalismo metodológico, lo que ha limitado en multitud de ocasiones los análisis de las movilidades en los campamentos de refugiados. Sin embargo, en los últimos años, autores como Cindy Horst (2003) y Nicholas van Hear (2009) han señalado la importancia del transnacionalismo en el análisis de las migraciones forzadas, así como la relevancia de los estudios diaspóricos a la hora de estudiar identidades y memorias colectivas dentro y fuera de los campamentos de refugiados. Los estudios diaspóricos se han centrado en aspectos relacionados con la identidad y las políticas de pertenencia de grupos de personas desde su lugar de origen hasta su lugar de destino (Brubaker, 2005) y en su vinculación con la noción de desplazamiento, que ha puesto en el centro del debate al territorio, las identidades y las memorias (Brah, 2011).

Esta confluencia se plasma en conceptos como el de "refugiados diaspóricos" de Van Hear (2009), quien argumenta que los nuevos flujos de movilidad de personas han dado lugar a un nuevo sujeto que se desplaza desde los campamentos de refugiados a territorios vecinos $u$ otros más lejanos. Estos procesos de movilidad producen nuevas estructuras sociales, proyectos políticos e identidades colectivas que impactan en el día a día de los campamentos de refugiados, lo que ha sido escasamente analizado. 
Del mismo modo, poco énfasis se ha hecho en la yuxtaposición de transnacionalismo e identidad, dos conceptos clave en el análisis de las movilidades de personas (Vertovec, 2001). La identidad ha sido uno de los conceptos sociales más escurridizos, pero que, en todo caso, remite a los modos en que grupos de personas se perciben y son, también, caracterizados por los demás. Las identidades son negociadas en múltiples espacios y son de suma relevancia en las estrategias transfronterizas (Appadurai, 1999). Todo lo anterior explica el desplazamiento de identidades enraizadas únicamente en los lugares, a otras que se mueven por diferentes escenarios o rutas. Denominadas identidades "híbridas" (García Canclini, 2001), "líquidas" (Bauman, 2001), "transnacionales" (Moraes, 2007), "cosmopolitas" (Malkki, 1995) son, en todo caso, identidades que tienen múltiples voces y están en continuo movimiento (Autant-Dorier, 2009). Además, compartir las memorias fija vivencias del pasado, certezas e incertezas del presente e imaginarios de futuro. Elena Fiddian-Qasmiyeh (2013) propone el concepto de "memorias viajeras", que permite comprender los efectos de las diferentes escalas de la memoria, que van desde lo íntimo a lo familiar y desde lo colectivo a lo nacional, construyendo identidades colectivas.

Lo cierto es que las vidas de muchas personas no pueden entenderse solo desde las fronteras nacionales o acotadas como tales. Las migraciones forzadas relacionan directamente el territorio de origen y el nuevo asentamiento humanitario, produciendo nuevas estructuras sociales, proyectos políticos e identidades colectivas en relación con esa experiencia migratoria y el devenir cotidiano en los campamentos. Sin embargo, la dilación de los conflictos genera también nuevos procesos de movilidad más allá del primer desplazamiento humanitario y es aquí donde convergen los estudios diaspóricos y el enfoque transnacional, aportando nuevas perspectivas al estudio de las migraciones forzadas (Almenara, 2017b).

Por ello, planteamos un nuevo enfoque en el análisis de los campamentos de refugiados de larga duración al entenderlos como espacios transnacionales, en el sentido de destacar sus conexiones transfronterizas y la creación de significados más allá de ellos. Entre estos campamentos y los territorios de la diáspora se rastrean numerosas prácticas que dictan gran parte del devenir cotidiano y de las identidades colectivas entre familias transnacionales, circuitos de intercambios, obligaciones y expectativas de los grupos implicados, 
colectivos que comparten y expresan identidades y, por último, entre organismos que se ubican en origen y destino.

\section{EL CASO SAHARAUI}

En esta segunda parte analizaremos cómo el "cronotopo del desastre" se articula con la construcción de la identidad nacional saharaui; recorre el tiempo que fluye desde el abandono del lugar de origen al momento actual y acompaña a la población saharaui (refugiados y descendientes) hacia los diversos lugares de la diáspora. Para ello, reflexionaremos, en la primera parte, sobre el impacto que supuso el colonialismo, el inicio del conflicto y el posterior exilio en la configuración de la identidad nacional saharaui $y$, en la segunda parte, sobre el papel de los procesos de movilidad de personas, bienes e informaciones en la reconfiguración de esta identidad nacional, poniendo especial atención en la emergencia de identidades múltiples y en el impacto de las nuevas tecnologías.

\subsection{La construcción de una identidad nacional: colonialismo y exilio}

Durante nuestro trabajo de campo en los campamentos de refugiados saharauis en Tinduf, en mayo de 2016, tuvimos la oportunidad de visitar el Museo de la Resistencia en Rabuni, centro administrativo de los campamentos saharauis. En este espacio se exhiben diversos objetos, carteles, banderas, fotografías y material armamentístico, introducidos por textos donde se narra parte de la memoria colectiva saharaui. En el recorrido por las diversas salas nos quedó patente la trayectoria de un desastre que se prolongaba desde la época colonial hasta el presente, marcado por el desplazamiento forzado, el trauma del abandono del lugar de origen y la supervivencia en los campamentos. El Museo de la Resistencia materializa la fijación del "cronotopo del desastre" y nos permite entender cómo la identidad nacional saharaui se encuentra atravesada por estos acontecimientos. 
Fotografía 1. Museo de la Resistencia, Rabuni (2016)

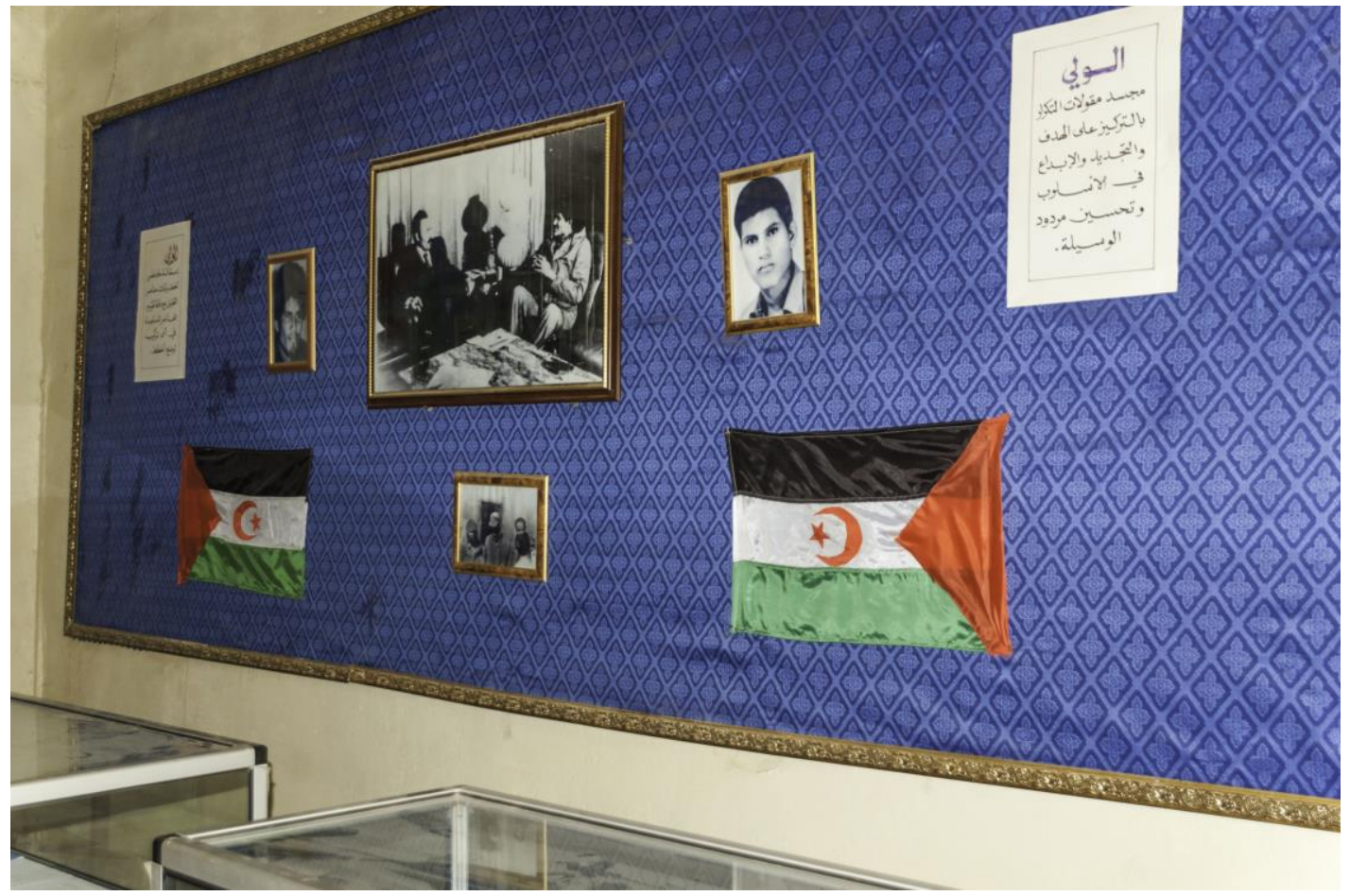

La exhibición del museo comienza con el impacto que supuso la intromisión extranjera en la región delimitada por los europeos como el Sáhara Español. El colonialismo español se ha presentado, por parte de la historiografía española, como benevolente y amistoso. Sin embargo, el intrusismo colonial basó su estrategia en la segregación, subordinación y marginalización de las poblaciones para el beneficio económico de la metrópoli (San Martín, 2010). A través de un sistema de incentivos se reformuló la estructura social de las diferentes qabilas (grupos tribales) del territorio (Bengochea, 2016) y se creó un sistema de lealtades que ayudó a la penetración pacífica en él. Para una población mayoritariamente nómada, la intrusión extranjera supuso la adaptación de su forma de vida a las nuevas exigencias de la metrópoli como, por ejemplo, el asentamiento en centros urbanos, la escolarización y la participación en las estructuras administrativas.

En 1964, España fue instada por parte del Comité de Descolonización de la Organización de las Naciones Unidas (ONU) a celebrar un referéndum de autodeterminación de la colonia. Empero, no fue hasta 1974 cuando se comenzó a realizar un censo de población del territorio con el objetivo de llevar a cabo el mandato del Comité. Durante esos años, 
grupos juveniles de diferentes qabilas, influenciados por los movimientos anticoloniales del continente, habian comenzado a considerar la independencia del territorio y, finalmente, en 1973 se conformó el Frente Polisario como principal movimiento de liberación (Wilson, 2016). Los jóvenes líderes del Frente Polisario habian comenzado a diseñar un proyecto político que pretendía conciliar los valores sociales de la tradición beduina con los valores políticos de la modernidad (Barona y Gamaliel, 2016), con el objetivo de reconstruir una "identidad dañada por la colonización" (Caratini, 2006: 7) a través de una transformación radical de la pertenencia. Para ello, el principal cambio era la abolición del tribalismo, que consideraban responsable de la colonización. La necesidad de ofrecer una respuesta coordinada y conjunta contra el colonialismo configuró la redefinición de las lógicas de poder de la sociedad beduina. Los jóvenes del Polisario consiguieron desafiar las relaciones jerarquizadas entre mayores y jóvenes a través de la transferencia de poder que se desarrolló al reconocer al Frente Polisario como único representante legítimo.

La decadencia de la dictadura franquista y la entrada de Marruecos al territorio a través de la Marcha Verde 3 provocaron la transferencia administrativa del por aquel entonces Sáhara Español a Marruecos y Mauritania a través de los Acuerdos Tripartitos de Madrid (14 de noviembre de 1975). El Frente Polisario exigió el derecho de descolonización a través de un referéndum de autodeterminación, pero la reclamación del territorio por parte de Marruecos, como región histórica del sultanato, paralizó la descolonización tras la salida de España en 1976. Estos acontecimientos están reflejados también en el Museo de la Resistencia como momentos clave que sobrevinieron al exilio.

A partir de ese momento se desató la Guerra del Sáhara, que provocó la huida de parte de la población, tras bombardeos de napalm, a la llamada hamada argelina en el sureste de Argelia, cerca de la ciudad de Tinduf. Esta zona había sido tradicionalmente Erguibat, una de las qabilas que conforman el pueblo saharaui, y alli se desplazaron diferentes poblaciones beduinas para unirse al Frente Polisario (San Martín, 2010). La población saharaui ${ }^{4}$ llegó a Tinduf traumatizada después de los

\footnotetext{
${ }^{3}$ Plan estratégico civil y militar que provocó la invasión marroquí del Sáhara español.

${ }^{4}$ Nos referimos a la población saharaui como aquella conformada por las diferentes qabilas que habitaban el Sáhara Occidental.
} 
bombardeos perpetuados por parte de la aviación marroquí, la urgencia de la huida y la separación de las familias durante el desplazamiento (Beristain y González, 2012). Agotada y desprovista de recursos, su asentamiento en los campamentos de refugiados supuso una anomalía radical tras la experiencia del desastre del colonialismo, la guerra y el éxodo, lo que ayudó a sentar las bases de la identidad nacional saharaui.

En los nuevos campamentos de refugiados el Frente Polisario consiguió llevar a cabo su proyecto político y reconfigurar las políticas de pertenencia, asociadas al tribalismo, a través de los principios de equidad y solidaridad. Su liderazgo efectivo se conformó sobre tres ejes prioritarios: apoyar a los soldados en el frente, proveer las necesidades básicas de los refugiados a través de comités y conformar las bases para una nueva sociedad (Farah, 2008). La emergencia de la situación y la necesidad de responder a la crisis planteada en el nuevo asentamiento humanitario consiguió configurar nuevos imaginarios sociales y nuevas identidades colectivas basadas en el trauma de las experiencias vividas por la población. El pasado permitió crear un proyecto político para el futuro, asentado en un agujero espaciotemporal (Bauman, 2002) que se convirtió en la sede de un nuevo Estado en el exilio, la República Árabe Saharaui Democrática (RASD) a partir del 27 de febrero de 1976. De esta manera, se produjo una fusión entre el Frente Polisario y la RASD, que se convirtió en un movimiento-Estado (Wilson, 2016).

Los campamentos de refugiados se configuraron siguiendo la estructura espacial de los campamentos nómadas (frigs), pero se otorgó mayor peso a la familia nuclear con el objetivo de debilitar la estructura de parentesco tribal (San Martín, 2010). Con esta medida, el Frente Polisario reforzaba la idea de comunidad y de colaboración de la tradición nómada, al mismo tiempo que pretendía romper con la estructura tribal que había caracterizado a la sociedad beduina. Las diferentes qabilas consiguieron encontrar los puntos en común de la nueva experiencia de los campamentos de refugiados a través de la convergencia de múltiples identidades colectivas dañadas por el desastre. Esta realidad fue asumida por parte de los diferentes grupos de forma pacífica, lo que refuerza las tesis de Agier (2001) y Malkki (1995) que consideran que la propia dificultad del asentamiento en los campamentos genera estrategias de identidad a través de la transformación y fusión de las identidades étnicas en identidades nacionales. Lo particular del caso saharaui se basa en que, desde el inicio, los campamentos se 
configuraron a través del liderazgo del Frente Polisario y de la declaración de la RASD como Estado en el exilio. Esto permitió asumir, desde ese primer momento, "el orden nacional de las cosas" (Malkki, 1995: 5) y constituir una nación que se fue configurando a través de las memorias colectivas asociadas al desplazamiento y al día a día en el campamento.

Otro punto fundamental fue el discurso de género y el papel relevante que se concedió a las mujeres en esta primera fase. El proyecto político del Frente Polisario se basaba en la igualdad y en la equidad, donde las mujeres tenían una posición significativa como símbolos de la nación y la transmisión de la cultura (Allan, 2010). Este enfoque respondía a la necesidad de articular un discurso movilizador para toda la sociedad y, al mismo tiempo, dar coherencia al combate y al campo de batalla. Efectivamente, desde el inicio del asentamiento en los campamentos, los hombres eran movilizados para el combate $y$, tal y como argumenta Joanna Allan (2010), la figura de la mujer se vinculó directamente con la nación; por tanto, defender a la mujer saharaui era salvaguardar a la nación de la invasión y del enemigo, así como respaldar la virilidad y el honor del hombre saharaui ante las aberraciones a las que sus mujeres se habían visto sometidas por la invasión marroquí.

El papel dado a la mujer saharaui fue el de transmisora de memorias colectivas a las nuevas generaciones (Yuval-Davis y Anthias, 1989). Como se refleja en las entrevistas que hemos realizado, las mujeres han sido portadoras de memorias impregnadas de signos del desastre, legitimando asi su participación en el nuevo proyecto de construcción de identidad. Esto se reafirma con el papel que asumieron en la organización y gestión de los campamentos de refugiados en los primeros años (Medina, 2014). Basándose en la división del trabajo de los campamentos nómadas, se hicieron con la organización de los comités de barrios, encargados de la distribución de tareas dedicadas a la educación, la salud, la producción, la distribución de alimentos y la justicia. Estaban acostumbradas a quedarse solas, mientras los hombres se dedicaban a los rebaños y al pastoreo (Juliano, 1998), por lo que asumian responsabilidades y tomaban iniciativas. Sophie Caratini (2006) señala que algunas de las actividades que realizaban en el campamento nómada, tales como el abastecimiento de agua y de madera, el 
recibimiento de extranjeros, la seguridad de la jaima ${ }^{5}$, etc. se trasladaron al quehacer de las mujeres en los campamentos de refugiados a través de los diferentes comités.

Por otro lado, la educación se conformó como una pieza clave en la transmisión del proyecto nacional. La elite del Polisario concebía la educación como una herramienta fundamental en la configuración de identidades colectivas asociadas al proyecto político y para ello desarrolló una estructura competente que formara al pueblo saharaui para un Sáhara occidental independiente. Además, como subraya Pablo San Martín (2010), los líderes del Polisario sabían que la educación era la esfera principal para reproducir el nacionalismo y la idea de una identidad colectiva saharaui. Por ello, la educación infantil fue promovida desde el inicio dentro de los campamentos. Se construyeron escuelas y se materializaron diferentes acuerdos con países como Argelia, Libia y Cuba para la escolarización secundaria y superior de chicos y chicas (Fiddian-Qasmiyeh, 2014). El Polisario creía firmemente en la formación de cuadros para el futuro Estado independiente, lo que se constituyó en una pieza fundamental del proyecto político.

Así pues, los campamentos de refugiados adquirieron un nuevo significado para la sociedad saharaui. Un espacio donde la seguridad del refugio y la búsqueda de salida a la anomalía del exilio asentaron la conformación de identidades colectivas asociadas a un proyecto político común. Es por ello que, como afirma Randa Farah (2008) en su comparativa entre el caso palestino y el saharaui, el éxito de los campamentos de refugiados saharauis reside en que fueron creados, desde el inicio, con una visión de futuro basada en la conformación de nuevas bases sociales para un posterior Estado independiente. Sin embargo, el devenir del conflicto ha desdibujado la temporalidad de los campamentos y el pueblo saharaui ha empezado a convivir en permanente espera. Esta demora se respira en el propio recorrido del Museo de la Resistencia, capaz de unificar estos acontecimientos y el anhelo de resolución del conflicto con el retorno al Sáhara occidental.

\subsection{La dilación del conflicto: movilidades y nuevas tecnologías}

La prolongación del conflicto y las transformaciones globales reconfiguran el "cronotopo del desastre" desde nuevos tiempos y

\footnotetext{
${ }^{5}$ Espacio habitacional, tiendas de tela utilizadas por las qabilas saharauis. 
lugares. A pesar de la retirada de Mauritania, Marruecos continuó su ofensiva. Tras el alto al fuego de 1991, la ONU pactó con ambas partes la celebración de un referéndum y creó una misión específica para ello, la Minurso. Esta parece estar en punto muerto desde principios de la primera década del siglo $\mathrm{XXI}$, lo que mantiene estancada la resolución del conflicto. Marruecos controla tres cuartas partes del territorio en la zona oeste, mientras que el Frente Polisario controla el lado este, los llamados territorios liberados. La población saharaui sigue dividida entre aquellos que viven en las zonas bajo control marroqui y aquellos que continúan desarrollando su vida en los campamentos de refugiados de Tinduf 41 años después. En la actualidad, no existen datos oficiales sobre el número de saharauis que residen en los campamentos, aunque algunas investigaciones apuntan que la población estimada es de 160.000 personas (Chatty, Fiddian-Qasmiyeh y Crivello, 2010).

A pesar de las esperanzas que despertaron con la creación de una misión de la ONU para la resolución del conflicto, dicho sentimiento se ha ido apagando entre los refugiados de Tinduf en vista del estancamiento de las negociaciones políticas. Los campamentos de refugiados saharauis se han convertido en espacios de espera (Agier, 2002), donde la población se ha visto abocada a normalizar su desplazamiento y su asentamiento en estos. Ello se ve reflejado en el abandono de las jaimas como residencias sustituidas por casas de adobe, aunque siguen presentes como parte del paisaje de la nostalgia y como símbolo de identidad en los campamentos de refugiados, como pudimos observar en nuestro trabajo de campo.

Caratini habla de "la prisión del tiempo" (2006: 19) como la nueva realidad de la población de los campamentos saharauis. Sin embargo, los campamentos de refugiados saharauis están cada vez más inmersos en procesos de movilidad de personas, bienes e informaciones, lo que nos invita a considerar la relevancia del enfoque transnacional a la hora de analizar la reconfiguración de políticas de pertenencia después del alto al fuego.

El fin de la guerra supuso una nueva redefinición de las dinámicas sociales de los campamentos. La vuelta de los hombres del frente, el abandono de la organización por comités y la introducción del dinero generaron un nuevo contexto social. 
La creación de una economía de mercado a través de la introducción del dinero con las primeras prestaciones procedentes de España -que antiguos empleados habían reclamado-y la reactivación de viejas rutas comerciales favorecieron la creación de mercados domésticos en los campamentos (San Martín, 2010). Más allá de la ayuda internacional y de la distribución de alimentos, la población saharaui podía, ahora, comprar en las pequeñas tiendas que fueron surgiendo. En nuestro trabajo de campo en los campamentos, pudimos observar el relevante papel que juegan las zonas comerciales -zocos- en la reactivación del día a día. Multitud de nuevos servicios han comenzado a aparecer: barberías, supermercados, pizzerías, panaderías, autoescuelas, talleres mecánicos, etc., aunque su supervivencia reside en la capacidad económica de las personas refugiadas, generalmente limitada y dependiente. En las entrevistas realizadas en Nuadibú (Mauritania) también quedan patentes las complejas redes de intercambios que se establecen entre los campamentos, las zonas que históricamente han sido paso de los desplazamientos nómadas y las diásporas saharauis.

También las nuevas tecnologías han permitido a los saharauis de los campamentos estar en contacto con sus familiares y amigos fuera de ellos gracias a los cibercafés y a los teléfonos móviles. Durante la primera década del siglo XXI surgieron los primeros cibercafés en los campamentos de Smara y El Aaiún, según nos comenta uno de sus antiguos trabajadores en una entrevista personal. Sin embargo, en 2010 aparecen las primeras tiendas de telefonía móvil gracias, sobre todo, a las posibilidades que ofrecía la conexión $4 \mathrm{G}$ en teléfonos móviles y en routers inalámbricos (Krogholt, 2015). 
Fotografía 2. Cibercafé en Rabuni (2016)

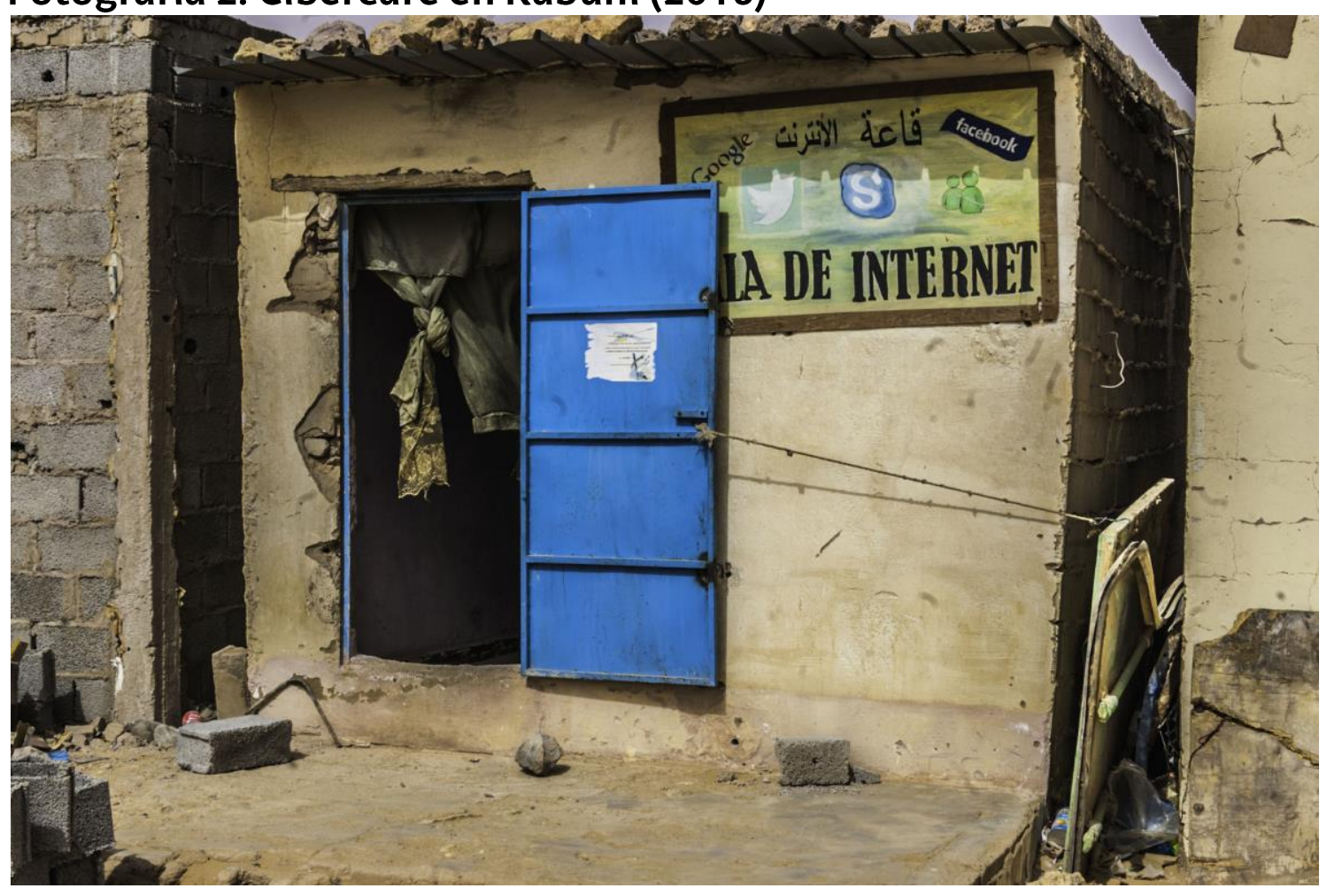

Así, pues, los campamentos se han convertido en un nuevo espacio donde la economía de mercado, aunque limitada, ha comenzado a expandirse. La limitación de la ayuda internacional, que no llega a cubrir las necesidades básicas de las familias, obliga a buscar nuevas formas de financiación en el espacio del refugio asociadas, igualmente, a la solidaridad internacional. Por ejemplo, el programa de cooperación Vacaciones en $\mathrm{Paz}^{6}$ aceleró la "capacidad de las familias de tener financiación extra a través de la solidaridad de familias españolas" (San Martín, 2010: 158). Todo lo anterior repercute en las estrategias transnacionales $y$, en especial, en las redes de ayuda y envío de remesas por parte de los familiares en el exterior o de las familias españolas. Estos envíos materiales se utilizan hoy para mejorar el nivel de vida, incluido un aspecto importante como es la comunicación a través de internet. Esto pudimos comprobarlo durante nuestra estancia en los

\footnotetext{
${ }^{6}$ Programa que permite que niños y niñas saharauis pasen los veranos en España con una familia de acogida. Al finalizar sus vacaciones suelen regresar con dinero que envían las familias.
} 
campamentos, ya que las familias que reciben remesas pueden acceder más fácilmente a la compra de un router y financiar el acceso a internet ${ }^{7}$.

Del mismo modo, la necesidad de encontrar un modo de subsistir en los campamentos o de intentar llevar a cabo un nuevo proyecto vital más allá de ellos ha generado nuevos procesos de movilidad migratoria a países como España, Francia, Mauritania y también Argelia a finales de la década de 1990. A estos territorios de las diásporas se traslada el "cronotopo del desastre", ahora con múltiples aristas que viajan, retornan y dialogan con los dilemas sobre la identidad de origen y destino.

Varios ejemplos pueden visibilizar estas paradojas que aúnan el desastre y las políticas de pertenencia. Un caso es el de personas que han emigrado con una experiencia previa de movilidad formativa fuera de los campamentos (Cuba, Libia, Siria o Argelia). La política de formación de cuadros en terceros países ha provocado una nueva fase de "ruptura emocional" (Gómez, 2011: 50) marcada por el doble desarraigo y el impacto del retorno a los campamentos de jóvenes que habían estudiado fuera. El choque ha sido aún mayor para aquellos que han pasado su adolescencia en países alejados del influjo cultural árabe, como Cuba. La estancia en la isla caribeña, durante períodos de más de diez años, ha conformado identidades híbridas asociadas a este proceso de movilidad. Los Ilamados cubarauis han experimentado un proceso de readaptación a su regreso a los campamentos. Estos jóvenes fueron estigmatizados debido a su comportamiento estridente en lo referente a "las costumbres y a la concepción cultural saharaui" (Boisha, 2015: 187), pero, con el paso del tiempo, han ido obteniendo mayor reputación debido a su gran valor formativo en áreas como la medicina o la educación. En las entrevistas realizadas se advierten los sentimientos encontrados entre las memorias del desastre, el alejamiento del contexto familiar y el regreso a los campamentos, donde las normas sociales y la falta de expectativas laborales les hacen tomar nuevas decisiones migratorias; estas, en muchos casos, se perciben como abandono y alejamiento de la realidad social en la que continúan sumergidos sus familiares y amigos.

\footnotetext{
${ }^{7}$ La conexión tiene un coste de 1000 dinares argelinos por $1 \mathrm{~GB}$ de conexión al mes; 1000 dinares argelinos equivalen, según fluctuación, a 9 euros, una cantidad asumible para aquellas familias con miembros en el extranjero o con conexiones con familias extranjeras.
} 
Otro caso es el de los niños y niñas acogidos a través del programa Vacaciones en Paz, quienes, en caso de poseer un cuadro médico delicado, permanecen en España con familias de acogida. Esta experiencia ha permitido a muchos adolescentes saharauis formarse en España y convivir con familias españolas, a diferencia de otras movilidades formativas en Cuba, Argelia o Libia, donde los jóvenes residian en alojamientos educativos. El cambio es importante, ya que se produce una socialización dual que genera otro tipo de identidades híbridas. En nuestras entrevistas se resalta su experiencia vital en la etapa de la infancia con sus familias en los campamentos de refugiados, así como su aprendizaje escolar en ellos. Estas memorias refuerzan su identificación como saharauis siempre atravesadas por sentimientos relacionados con el desastre que, en su mayor parte, se centran en las duras condiciones de vida en los campamentos. Sin embargo, su convivencia en España ha reconfigurado su propia identidad a través del devenir cotidiano con sus familias de acogida. Esto lo pudimos observar cuando preguntábamos por sus padres y nos respondían frases similares a "¿Te refieres a mis padres biológicos o a los de aquí?", haciéndonos ver su pertenencia a familias transnacionales. Estos procesos de movilidad han creado desarrollos de la identidad más complejos, que van más allá de los campamentos de refugiados y provocan tensiones en la construcción de la identidad nacional saharaui, tambaleada por la necesidad de los jóvenes de llevar a cabo su propio proyecto vital en el exterior, con evidentes consecuencias en la conformación de identidades (Gimeno, 2007).

Lo cierto es que estas experiencias diaspóricas parecen estar reconstruyendo recuerdos cada vez más alejados de la memoria local del desastre. Por tanto, ese "cronotopo del desastre", inicialmente localizado en los campamentos y recientemente reconfigurado por estas movilidades de personas, se enlaza estrechamente con las transformaciones de la identidad, restructuradas hacia lo global a través de pertenencias más fluidas, híbridas o múltiples.

Efectivamente, los flujos de movilidad de personas han tenido un impacto directo en la circulación de la información dentro y fuera de los campamentos de refugiados. En este sentido, internet parece estar jugando un papel fundamental en la reconfiguración tanto de dicho cronotopo como de las identidades: por una parte, las imágenes, informaciones, videos, etc. que se vierten en la red exaltan las 
dificultades y los traumas del pueblo saharaui, aunque, por otra parte, también internet refleja las tensiones originadas por los procesos migratorios. En varias entrevistas, algunas jóvenes explicitan las dificultades que tienen para subir fotos personales a sus propios perfiles de Facebook, al ser objeto de comentarios vejatorios, basados en su forma de vestir o de posar, por parte de sus familiares y amigos en los campamentos. Muchas de las entrevistadas, residentes en España, citan cómo se refieren a ellas a través de la palabra nasariyya, que si bien siempre ha servido para nombrar a las mujeres blancas extranjeras que visitan los campamentos (Fiddian-Qasmiyeh, 2014), en la actualidad también define a estas chicas que están "occidentalizadas" y que no visten la $\mathrm{melfa}^{8}$. Un caso muy relevante y comentado en redes ha sido el de la actriz saharaui Mariam Bachir, que recibió numerosas críticas en su perfil de Twitter e Instagram por el vestido que lució en la gala de los Goya de 2015. Lo anterior podría explicar por qué muchas jóvenes referencian que prefieren tener dos perfiles de Facebook, uno para sus familias en los campamentos y otro para sus amistades y compañeros en España.

En resumen, los flujos de movilidad e información han conseguido vincular a los saharauis de dentro y de fuera de los campamentos, reconfigurando el "cronotopo del desastre" desde lo local hacia lo global, asentándolo más en los derechos humanos, la solidaridad internacional y las pertenencias múltiples. Desde una identidad nacional fuertemente arraigada en los campamentos surgen identidades transnacionales que intentan plantear su propio camino: tienen presente la memoria colectiva del desastre alargado y el trauma del exilio de la población que continúa en los campamentos, aunque comienzan a redefinir las políticas de pertenencia desde otros ángulos más cosmopolitas y globales.

\section{CONSIDERACIONES FINALES}

En estas páginas se han presentado dos argumentos transversales desde los que analizar la construcción de memorias e identidades en campamentos de refugiados de larga duración. Por una parte, lo que se ha denominado el "cronotopo del desastre" es una narrativa que atraviesa la construcción de memorias e identidades, que se alarga en

\footnotetext{
${ }^{8}$ Tela tradicional femenina que cubre el cuerpo y el cabello de las mujeres saharauis. 
tiempos y espacios. Tiempos, porque este cronotopo se reconstruye de las primeras a las siguientes generaciones, bajo un prisma que añade o difumina detalles, momentos y protagonistas, siempre mediados por las relaciones de poder y las políticas de pertenencia. Espacios, porque los campamentos de refugiados son territorios humanitarios, donde se concentran violencias, traumas, exilios, así como la pérdida de los referentes de los lugares de origen; pero, también, son territorios transnacionales, donde confluyen numerosas movilidades, más allá de la visión estática que se presenta sobre ellos. Por tanto, si bien este "cronotopo del desastre" surge estrechamente vinculado a lo local, en los campamentos de refugiados, los procesos transnacionales permiten que viaje y sea reconstruido en los nuevos asentamientos migratorios. Y es aqui donde surgen nuevas subjetividades e identidades híbridas que redefinen políticas de pertenencia hacia lo global.

El caso saharaui se ha analizado a través de dos etapas de construcción de la identidad: una, asociada al exilio y la construcción nacional; la otra, caracterizada por los procesos de movilidad y el impacto de las nuevas tecnologías. En la primera, el eje del desastre se remonta a la etapa colonial, tal y como se exhibe en el Museo de la Resistencia de los campamentos saharauis. El exilio y las propias condiciones del campamento asientan el proceso de construcción de una identidad nacional basada en el trauma del desplazamiento, en principios de equidad y en una visión de futuro para un Estado independiente. Sin embargo, el estancamiento de la situación propicia una segunda etapa, dominada por la aceleración de las movilidades de personas, bienes y símbolos, atravesada por los posicionamientos de las nuevas generaciones, la fluidez y la introducción de las nuevas tecnologías. Estos cambios se expresan claramente a través de los procesos migratorios y del uso de internet, que consigue visualizar el surgimiento de nuevas subjetividades, dentro y fuera de los campamentos de refugiados. Desde estas identidades híbridas se aprecian disonancias, conflictos y nuevas agencias, que dependen de escenarios y de trayectorias individuales, genéricas y generacionales. Sin embargo, todas estas voces se aúnan a través de un hilo conductor común: un discurso sobre la identidad fuertemente arraigado y un proyecto de futuro construido a través de las memorias continuamente reelaboradas sobre un desastre prolongado. 
Todo lo anterior apoya nuestra apuesta por el enfoque transnacional para comprender estas realidades dentro y fuera de los campamentos de larga duración. En las últimas décadas, esta perspectiva ha servido para repensar las fronteras, la movilidad humana, las conexiones entre territorios y las identidades colectivas, pero también ha cuestionado enfoques y conceptos centrales en las ciencias sociales, reformulando nociones como sociedad, cultura, identidad y espacio, antes encerradas en fronteras estatales. Si bien resulta evidente que el transnacionalismo es un campo donde los consensos están por llegar, los retos futuros pasan por el desafío a las tendencias del nacionalismo metodológico, esencialismos y posicionamientos de los investigadores (Faist, 2012). Desde las ciencias sociales, necesitamos aprender a deslizarnos de modo más fluido entre la teoría y la práctica de lo social, visibilizando las "tendencias globales y subterráneas" (Sassen, 2015: 16).

Por tanto, se ha destacado la construcción de estos "santuarios humanitarios" como ejemplo de la brutalidad del sistema mundial que mantiene a millones de personas almacenadas en prisiones de tiempo, espacio y de trayectorias vitales. El control de los organismos internacionales y de las mismas ONG construyen un sujeto desposeído y victimizado. Así, la configuración de los espacios de los campamentos, el alargamiento de la espera y las lógicas de las movilidades a lo largo del tiempo reconfiguran ese "cronotopo del desastre" que canaliza memorias, identidades y resistencias que se fijan desde múltiples vértices en las trayectorias vitales de mujeres, hombres, niños, niñas y de las sucesivas generaciones.

\section{BiBLIOGRAFÍA}

ACNUR. (2016). Tendencias Globales. Desplazamiento forzado en 2015. Forzados a huir. Disponible en: http://www.acnur.org/t3/fileadmin/Documentos/Publicaciones/2 016/10627.pdf

Ager, A. (2014). Health and Forced Migration. En E. Fiddian-Qasmiyeh, G. Loescher, K. Long y N. Sigona (Eds.). The Oxford Handbook of Refugee and Forced Migration Studies (pp. 433-446). Oxford: Oxford University Press.

Agier, M. (2002). Between war and the city. Towards an urban anthropology of refugee camps. Ethnography, 3(3), 317-341. 
Allan, J. (2010). Imagining Saharawi women: The question of gender in Polisario discourse. The Journal of North African Studies, 15(2), 189202.

Almenara Niebla, S. (2017a). Diásporas digitales: una aproximación feminista al estudio de las minorías on-line. El caso de la diáspora saharaui. En R. Cotarelo y J. Gil (Eds.). Ciberpolítica. Gobierno abierto, redes, deliberación, democracia (pp. 341-362). Madrid: Instituto Nacional de Administración Pública.

Almenara Niebla, S. (2017b). Entendiendo las migraciones forzadas a través de los estudios diaspóricos. Un análisis con perspectiva de género. Astrolabio. Revista internacional de filosofía, 19, 298-306.

Appadurai, A. (1996). Modernity at large. Cultural dimension of globalization. Minneapolis: University of Minnesota Press.

Appadurai, A. (1999). Soberanía sin territorialidad: notas para una geografía postnacional. Nueva Sociedad, 163, 109-125.

Ascanio Sánchez, C. (2007). Género, tradición e identidades. Las Palmas de Gran Canaria: Anroart Ediciones.

Autant-Dorier, C. (2009). Saisir les identités en mouvement: parenté et histoires de familles turques en migration. Revue européenne des migrations internationales, 25(3), 132-151.

Bajtín, M. (1996). The Dialogic Imagination. Four Essays. Austin: University Texas Press.

Barona, C., y Gamaliel, J. (2016). La República Árabe Saharaui Democrática. Reflexiones sobre un estado en el exilio. En I. Barrañeda y R. Ojeda (Eds.), Sáhara Occidental. 40 años después (pp. 57-66). Madrid: Ed. Catarata.

Bauman, Z. (2001). Identity in the Globalising World. Social Anthropology, 9(2), 121-129.

Bauman, Z. (2002). Society under siege. Cambrige: Polity Press.

Bengochea, E. (2016). Políticas imperiales y género. La Sección Femenina en la Provincia del Sáhara (1961-1975) (Tesis doctoral inédita). Universitat de València, Valencia.

Beristain, C., y González, E. (2012). El oasis de la memoria. Memoria histórica y violaciones de derechos humanos en el Sáhara occidental. Tomo I. Bilbao: Universidad del País Vasco/Hegoa.

Boisha, L. (2015). Sáhara Occidental, Cuba y España: Nuestros sueños se juntan en una misma ola. Transmodernity. Journal of Peripheral Cultural Production of the Luso-Hispanic World, 5(3), 179-194. 
Brah, A. (2011). Cartografías de la diáspora. Identidades en cuestión. Madrid: Traficantes de Sueños.

Brubaker, R. (2005). The "diaspora" diaspora. Ethnic and Racial Studies, 28(1), 1-19.

Caratini, S. (2006). La prisión del tiempo: Los cambios sociales en los campamentos de refugiados saharauis. Cuadernos Bakeaz, 77, 121.

Chatty, D., Fiddian-Qasmiyeh, E., y Crivello, G. (2010). Identity with/out Territory: Sahrawi Refugee Youth in Transnational Space. En D. Chatty (Ed.). Desterritorialized Youth. Sahrawi and Afgan Refugees at the Margins of the Middle East (pp. 37-84). Oxford: Berghahn Books.

Coraza, E. (2014). Territorialidades de la migración forzada. Los espacios nacionales y trasnacionales como estrategia política. Espacialidades. Revista de Temas Contemporáneos sobre Lugares, Politica y Cultura, 4(1), 197-221.

Deubel, T. (2015). Mediascapes of Human Rights: Emergent Forms of Digital Activism for the Western Sahara. Transmodernity: Journal of Peripheral Cultural Production of the Luso-Hispanic World, 5(3), 6-19.

Faist, T. (2000). Transnationalization in International Migration. Implications for the Study of Citizenship and Culture. Ethnic and Racial Studies, 23, 189-222.

Faist, T. (2012). Toward a Transnational Methodology: Methods to Address Methodological Nationalism, Essentialism, and Positionality. Revue Européenne des Migrations Internationales, 28(1), 51-70.

Farah, R. (2008). Refugee Camps in the Palestinian and Sahrawi National Liberation Movements: A comparative perspective. Journal of Palestine Studies, 38(2), 76-93.

Feldman, I. (2015). What is a camp? Legitimate refugee lives in spaces of long-term displacement. Geoforum, 66, 244-252.

Fiddian-Qasmiyeh, E. (2013). Transnational childhood and adolescence: Mobilizing saharawi identity and politics across time and space. Ethnic and Racial Studies, 36(5), 875-895.

Fiddian-Qasmiyeh, E. (2014). The ideal refugees. Gender, Islam and Saharawi politics of survival. Nueva York: Syracuse University Press. 
García Canclini, N. (2001). Culturas híbridas. Estrategias para entrar y salir de la modernidad. Barcelona: Paidós.

Gimeno, J. C. (2007). Transformaciones socioculturales de un proyecto revolucionario: la lucha del pueblo saharaui por la liberación. Caracas: Programa Cultura, Comunicación y Transformaciones Sociales/ Universidad Central de Venezuela. Disponible en: https://www.academia.edu/11802089/Transformaciones_sociocul turales_de_un_proyecto_revolucionario_la_lucha_del_pueblo_Sa haraui_por_la_liberaci\%C3\%B3n

Gómez, C. (2011). La migración saharaui en España. Estrategias de visibilidad en el tercer tiempo del exilio. Leipzig: Editorial Académica Española.

Grimson, A. (2011). Los limites de la cultura. Critica de las teorias de la identidad. Buenos Aires: Siglo XXI.

Guarnizo, L. (2003). The Economics of Transnational Living. International Migration Review, 37(3), 666-699.

Hajdukowski-Ahmed, M. (2009). A dialogical approach to identity. Implications for refugee women. En M. Hajdukowski-Ahmed, N. Khanlou y H. Moussa (Eds.). Not Born a Refugee Women. Contesting identities, rethinking practices (pp. 28-54). Oxford: Berghahn Books.

Hall, S. (2010). Sin garantías. Trayectorias y problemáticas en estudios culturales. Bogotá: Instituto de Estudios Sociales y Culturales Pensar/Universidad Javeriana/Universidad Andina Simón Bolivar.

Horst, C. (2003). Transnational nomads: How Somalis cope with refugee life in the Dadaab camps of Kenya. Oxford: Berghahn Books.

Juliano, D. (1998). La causa saharaui y las mujeres: "Siempre hemos sido muy libres». Barcelona: Icaria.

Kivisto, P. (2001). Theorizing Transnational Migration: A Critical Review of Current Efforts. Ethnic and Racial Studies, 24(3), 549-577.

Krogholt, M. (2015, junio 26) Saharawis use information communication technologies in their fight for independence. Afrika Kontakt. Disponible en: http://www.afrika.dk/article/saharawis-useinformation-communication-technologies-their-fightindependence

Lacroix, T., y Fiddian-Qasmiyeh, E. (2013). Refugee and Diaspora Memories: The Politics of Remembering and Forgetting. Journal of Intercultural Studies, 34(6), 684-696. 
Levitt, P., y Glick Schiller, N. (2004). Perspectivas internacionales sobre migración: conceptualizar la simultaneidad. Migración y Desarrollo, 3, 60-90.

Loizos, P. (2007). 'Generations' in Forced Migration: Towards Greater Clarity. Journal of Refugee Studies, 20(2), 193-209.

Malkki, L. (1995). Purity and exile: Violence, memory, and national cosmology among Hutu refugees in Tanzania. Chicago: The University of Chicago Press.

Medina, R. (2014). Resistencias, identidades y agencias en las mujeres saharauis refugiadas. Revista Internacional de Pensamiento Politico - IÉpoca, 9, 163-181.

Moraes, N. (2007). Identidad transnacional, diáspora/s y nación: Una reflexión a partir del estudio de la migración uruguaya en España. En D. Mato y A. Maldonado (Eds.). Cultura y transformaciones sociales en tiempos de globalización. Perspectivas latinoamericanas (pp. 181-197). Buenos Aires: Clacso.

O'Reilly, K. (2012). International Migration and Social Theory. Houndmills: Palgrave MacMillan.

Portes, A., Guarnizo, L., y Landolt, P. (1999). The study of transnacionalism: pitfalls and promise of an emergent research field. Ethnic and Racial Studies, 22(2), 217-237.

San Martín, P. (2010). Western Sahara. The Refugee Nation. Cardiff: University of Wales Press.

Sassen, S. (2015). Expulsiones. Brutalidad y complejidad en la economía global. Buenos Aires: Katz.

Sigona, N. (2014). The politics of refugee voices: representations, narratives, and memories. En E. Fiddian-Qasmiyeh, G. Loescher, K. Long, y N. Sigona (Eds.). The Oxford Handbook of Refugee and Forced Migration Studies (pp. 369-382). Oxford: Oxford University Press.

Turton, D. (2003). Refugees and 'Other Forced Migrants'. RSC Working Paper Series No.13. Oxford: Refugees Studies Center. Disponible en: https://www.rsc.ox.ac.uk/files/publications/working-paperseries/wp13-refugees-other-forced-migrants-2003.pdf

Van Hear, N. (2009). The rise of refugee diasporas. Current History, 108(717), 180-186.

Vertovec. S. (2001). Transnacionalism and Identity. Journal of Ethnic and Migration Studies, 27(4), 573-582. 
Wilson, A. (2016). Sovereignty in Exile. A Saharan Liberation Movement Governs. Philadelphia: University of Pennsylvania Press.

Yuval-Davis, N. y Anthias, F. (1989). Introduction. En N. Yuval-Davis, y F. Anthias (Eds.). Woman-Nation-State (pp. 1-15). Nueva York: Palgrave MacMillan. 